\title{
Do smokers benefit from dental hygiene oral prophylaxis? A Nigerian pilot study
}

\section{S.O. Nwhator ${ }^{1}$ and O. Olagundoye ${ }^{1}$}

$$
\begin{aligned}
& \text { هل يستفيد المدخِّنون من الوقاية الفموية لصحة الأسنان: دراسة تجريبية من نيجيريا }
\end{aligned}
$$

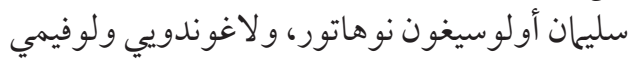

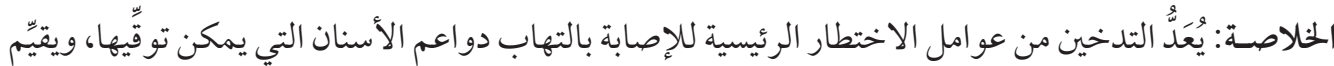

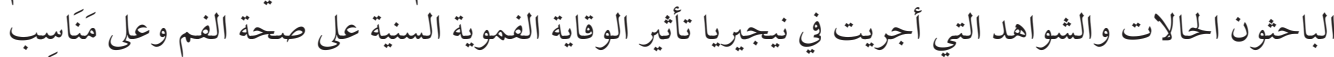

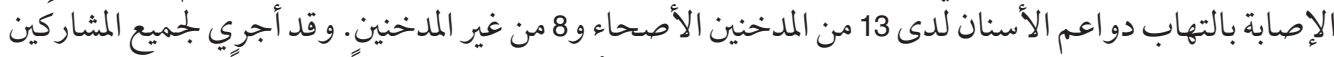

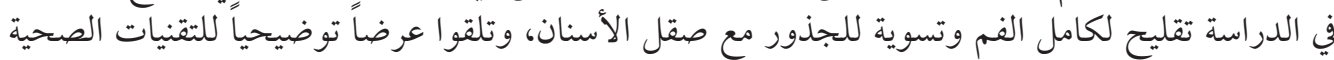

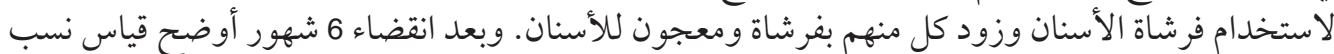

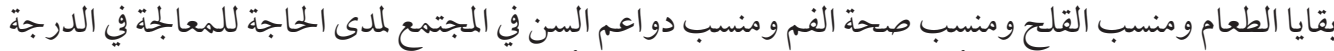

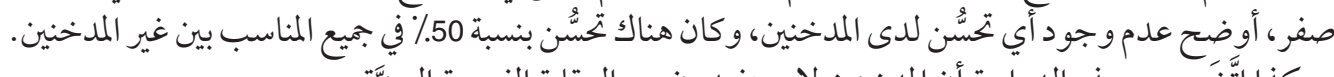

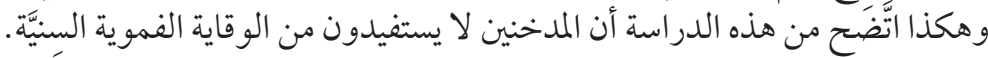

ABSTRACT Smoking is a major, preventable risk factor for periodontitis. This pilot study in Nigeria evaluated the effect of dental oral prophylaxis on oral hygiene and periodontal indices among 13 systemically healthy smokers and 8 non-smokers. All participants received full-mouth scaling and root planing, tooth polishing, demonstration of correct brushing technique and a new toothbrush and toothpaste. After 6 months, debris index, calculus index, oral hygiene index and community periodontal index of treatment needs status code 0 scores showed no improvement in smokers. There was a $50 \%$ improvement of all indices among non-smokers. Smokers showed no benefit from dental oral prophylaxis in this study.

\begin{abstract}
Les fumeurs tirent-ils un bénéfice de la prophylaxie visant à améliorer l'hygiène bucco-dentaire ? une étude pilote au Nigéria

RÉSUMÉ Le tabagisme est un facteur de risque important de la parodontite qui peut être évité. Cette étude pilote au Nigéria a évalué les effets de la prophylaxie bucco-dentaire sur l'hygiène buccale et les indices parodontaux de 13 fumeurs en bonne santé générale et 8 non-fumeurs. Tous les participants ont été soumis à un détartrage-surfaçage radiculaire complet et à un polissage des dents, ils ont assisté à une démonstration des bonnes techniques de brossage, et une nouvelle brosse à dents et du dentifrice leur ont été remis. Six mois plus tard, le code 0 obtenu pour l'état des sujets au regard de l'indice de débris, de l'indice de tartre, de l'indice d'hygiène buccale et de l'indice communautaire des besoins en soins parodontaux a montré qu'il n'y avait eu aucune amélioration chez les fumeurs. On a constaté une amélioration de $50 \%$ de tous les indices chez les non-fumeurs. Cette étude a montré que les fumeurs ne tiraient pas de bénéfice de la prophylaxie bucco-dentaire.
\end{abstract}

${ }^{1}$ Department of Preventive and Community Dentistry, Obafemi Awolowo University, Ile-Ife, Nigeria (Correspondence to: nwhator32@yahoo.com).

Received: 31/10/06; accepted: 05/02/07 


\section{Introduction}

In addition to the well-known adverse health effects of tobacco use such as cardiovascular disease, pulmonary disease and various carcinomas $[1-4]$, there are serious orodental health effects, including dental aesthetic effects in the form of tooth stains and halitosis [5], alteration of the mucous membrane barrier, leukoplakia (smoker's keratosis), nicotina palati, submucous fibrosis, vitiligo (leukoderma), hairy tongue, precancerous transformations of the oral mucosa [5] as well as severe periodontitis [6]. Tomar and Asma in the NHANES III [Third National Health and Nutrition Examination Survey] in the United States of America found that smokers suffered more severe periodontitis than non-smokers [7]. Baab and Oberg reported irreversible microvascular changes in the gingiva in dogs [8]. Dietrich et al. in a recent German study reported that "smoking exerts a strong, chronic, and dosedependent suppressive effect on gingival bleeding on probing" [9]. Barbour et al. observed that smokers exhibited increased numbers of peripheral blood mononuclear phagocytes, but these phagocytes were functionally compromised [10], while Zambon et al. concluded that cigarette smoking favours subgingival infection with periodontopathic organisms [11].

Dental studies have reported that smokers have a greater amount of plaque and calculus deposits than their non-smoking counterparts of comparable age [12-14], although some other studies found no such differences [15]. Reasons suggested for the differences include smokers' general attitude of neglect [16], ineffective toothbrushing [17] and greater mineralization potential of plaque fluid in smokers [18].

This pilot study in Nigeria evaluated whether a session of dental hygiene oral prophylaxis and training had an effect on oral hygiene and periodontal indices among smokers and non-smokers.

\section{Methods}

\section{Study design and sample}

A cross-sectional field survey was carried out among factory workers in Lagos state, Nigeria. The participants treated in the current study were all seen in a dental hospital in Lagos in the year 2004. They were 21 systemically healthy adult volunteers (13 non-smokers and 8 smokers), selected by convenience sampling; $76 \%$ were under 45 years of age. In a dental examination, oral hygiene and periodontal status scores were recorded for all participants before they received a dental hygiene oral prophylaxis. Six months after the intervention the scores were evaluated again.

\section{Research instruments/periodontal examination}

A single dentist carried out all examinations and scorings and performed all treatments and surgery required by the participants.

\section{Oral hygiene}

Debris index scores (DIS) and calculus index scores (CIS) were recorded for both smoker and non-smoker groups. DIS and CIS are 2 components of the oral hygiene index score (OHIS), a composite index [19]. It measures level of debris and calculus accumulation on the clinical (visible) crown of the tooth. In line with this index, participants were scored as follows: $0=$ debris, plaque and calculus-free surface, $1=$ deposits covering up to one-third of clinical tooth crown, $2=$ deposits covering two-thirds of crown and $3=$ deposits covering beyond two-thirds of tooth crown surfaces. The DIS and CIS were obtained for each patient and the OHIS calculated as: $\mathrm{OHIS}=\mathrm{DIS}+\mathrm{CIS} / 6$. 


\section{Periodontal status}

The study also evaluated the status codes of the community periodontal index of treatment needs (CPITN) for each patient. The CPITN is an internationally recognized index developed by Ainamo et al. and adopted for use by the World Health Organization [20]. It is useful in the rapid examination of the periodontal status and treatment needs of a given population. It comprises 5 status codes (0-4), and their corresponding 5 treatment need codes $(0-\mathrm{IV})$. The status codes are: $0=$ no sign of disease (healthy periodontium); 1 = gingival bleeding on gentle probing; 2 = supra/subgingival calculus present; 3 = shallow pathological pockets $(4-5 \mathrm{~mm}) ; 4=$ deep pathological pockets $(>6 \mathrm{~mm})$.

The mouth was divided into sextants. The individual's CPITN maximum score was the worst score in the sextants. Only status codes 0 and 2 were used in the current study because the time-scale of the pilot study was too short to detect any changes in pocket depth [21].

\section{Intervention}

Smoking status was recorded for all participants. Smoking was defined as currently smoking $1+$ cigarettes per day. The sample were predominantly mild smokers; 60\% had smoked for less than 10 years and over $60 \%$ smoked only $1-4$ cigarettes daily.

After the pre-evaluation recordings of the OHIS and CPITN scores, all participants received a session of dental hygiene prophylaxis. Each participant was given full-mouth scaling and root planing (if indicated), meticulous tooth polishing, individualized practical demonstration of correct brushing technique, a new toothbrush and toothpaste of the same brand, and instructions on twice daily brushing. All the treatments, demonstrations and instructions were given by a single examiner. No smoking cessation counselling was given until the end of the 6-month evaluation period.

Six months after the intervention the OHIS and CPITN scores were evaluated again by the same examiner. Recordings of pre- and post-evaluation recordings were made on different sheets to blind the examiner to both the smoking status and the preevaluation recordings of the participants.

\section{Data analysis}

Data entry and analysis were done using Epi-info, version 6, using simple intra-group analysis. Chi-squared statistics were used to determine statistical significance at $P<0.05$.

\section{Results}

Table 1 shows the OHIS and CPITN scores and percentage improvement/deterioration before and after the intervention. Smokers showed no change in mean total OHIS score (8.0) (scores for DIS and CIS were 4.0 re-

\begin{tabular}{|c|c|c|c|c|c|c|}
\hline \multirow[t]{3}{*}{ Smoking status } & \multirow{2}{*}{\multicolumn{2}{|c|}{ OHIS (mean score) }} & \multicolumn{4}{|c|}{ CPITN status (no. of sextants) } \\
\hline & & & \multicolumn{2}{|c|}{ Code 0 (healthy) } & \multicolumn{2}{|c|}{ Code 2 (calculus) } \\
\hline & Before/after & $\%$ change & Before/after & $\%$ change & Before/after & $\%$ change \\
\hline Smokers $(n=13)$ & $8.0 / 8.0$ & 0.0 & $29 / 29$ & 0.0 & $14 / 15$ & -7.1 \\
\hline $\begin{array}{l}\text { Non-smokers } \\
\quad(n=8)\end{array}$ & $\begin{array}{c}15.6 / 7.8 \\
\chi^{2}=11.0, \mathrm{df}=\end{array}$ & $\begin{array}{c}+50.0 \\
1, P<0.001\end{array}$ & $\begin{array}{c}33 / 56 \\
\chi^{2}=2.4, d f=\end{array}$ & $\begin{array}{c}+69.7 \\
1, P=0.121\end{array}$ & $\begin{array}{c}41 / 19 \\
\chi^{2}=3.33, \mathrm{df}=\end{array}$ & $\begin{array}{c}-53.7 \\
1, P=0.067\end{array}$ \\
\hline
\end{tabular}


spectively) at baseline and post-evaluation (8.0). The mean OHIS score of non-smokers, however, improved from 15.6 to $7.8\left(\chi^{2}\right.$ $=11.0, \mathrm{df}=1, P<0.001)$ (scores for DIS and CIS were 7.8 and 3.9 respectively).

Smokers had a total of 29 sextants with CPITN status code 0 (healthy sextants) at baseline and same figure at post-evaluation, while the number of healthy sextants in non-smokers improved from 33 before to 56 after $\left(\chi^{2}=2.4\right.$, df $\left.=1, P=0.121\right)$. Smokers had 14 sextants with CPITN status code 2 (calculus) at baseline and 15 sextants at the 6-month post evaluation recordings, while non-smokers improved their dental status from 41 code 2 sextants before to only 19 sextants after intervention $\left(\chi^{2}=3.33, \mathrm{df}=1\right.$, $P=0.067)$.

\section{Discussion}

Even though the detrimental effects of smoking on periodontal health are well documented [22-26], not much has been reported about smokers and non-smokers whose oral hygiene and periodontal status are standardized at baseline. Findings from the current study show the ineffectiveness of proprietary smokers' toothbrushes and dentifrices. These products might at best palliate smokers' aesthetic concerns, but do not address their more deep-seated periodontal problems. Our findings suggest that the periodontal effects of smoking are neither plaque-related nor locally controlled, but in fact are systemically-mediated. This corroborates several previous studies [23-26].

Statistical analysis of the data revealed a highly significant difference between the pre- and post-evaluation measurements of oral hygiene between smokers and nonsmokers. Comparisons of differences in CPITN scores did not attain statistical significance. This is not surprising because the
CPITN is not as sensitive an index as the OHIS [27,28].

The 50\% improvement in oral hygiene among non-smokers compared with no improvement among smokers is not only of concern, considering the short evaluation period, but also strongly suggestive that smokers benefit little or nothing from oral hygiene prophylaxis. Moreover, a nearly $70 \%$ increase in the number of healthy sextants among non-smokers compared with no improvement in smokers, as well as a $54 \%$ decrease in the sextants with calculus among smokers as against a 7\% increase among non-smokers seems to confirm this observation. The huge difference in the number of sextants with CPITN status code 2 between the 2 groups is explained by the greater mineralization potential of plaque fluid, which in turn can be explained by 2 phenomena in smokers: the greater salivary concentration of calcium and phosphate ions and the increased salivary $\mathrm{pH}$ [18].

Natto et al. in a study of tobacco smoking and periodontal health in a Saudi Arabian population found a statistically significant association between smoking and probing depth [29]. The current study did not assess differences in probing since the 6-month observation period was too short to note any significant differences in pocket depth. Our study used simple, universally acceptable indices. Emphasis has been rightly placed on measuring pocket formation since it is a reproducible linear indicator of chronic periodontitis [30]. However, advanced imaging techniques such as subtraction radiography [31] and computer-assisted densitometric image analysis [32] are not readily available in developing countries such as Nigeria. In addition, it takes an average of 5 years to lose $1 \mathrm{~mm}$ of alveolar bone height [21], thus making it impracticable to use it as index in a short-term pilot study such as this.

المجلة الصحية لشرق المتوسط، منظمة الصحة العالمية، المجلد الخنامس عشر، العدد ع، 9 +. 
Despite these limitations and the limitations of the small sample size and the relatively short evaluation period of this pilot study, we feel that the findings should be viewed seriously considering the large differences recorded between smokers and non-smokers as well as the fact that the smokers included in this study were mostly light (mild) smokers, in line with criteria set by Schwartz-Arad et al. [33], and modified by Nwhator [13]. Considering previous reports on the dose-response effect of smoking on the periodontium $[9,34,35]$, the differences between smokers and nonsmokers as observed in our study could be described as profound and could be even worse in heavy smokers.

These results are even more important when we consider that within the last decade attention has shifted to the mouth as a likely route of penetration of aggravating factors which complicate already existing systemic diseases. This shift in attention is based on intriguing findings from studies carried out especially within the last decade, such as normative ageing [36] and a study which found that traditional risk factors do not explain a large number of patients with coronary arteriosclerosis [37].
Other studies in this regard include those of Mattila et al. [38] who found an independent association between poor periodontal health and myocardial infarction, Syrjanen et al. [39] found that $25 \%$ of stroke patients as against $2.5 \%$ of controls had poor periodontal health and Offenbacher et al. [40] who reported that known risk factors do not account for $25 \%$ of cases of preterm low-birth-weight babies, while Hyman and Reid [41] noted that their results "suggest that cigarette smoking may be a cofactor in the relationship between periodontal disease and chronic obstructive pulmonary disease."

\section{Conclusions}

The findings from the current study support the widely reported observation that the effects of smoking on the periodontal support apparatus are not plaque-related but systemically-mediated. If the differences are so marked in mild smokers, then the situation would more serious in heavy smokers. We conclude that dental hygiene oral prophylaxis is of little or no benefit to smokers.

\section{References}

1. Igwe SA. Nigeria's youth at risk. African health, 1992, 14(4):45-6.

2. Elegbeleye OO. Bronchial carcinoma in Nigerians. A report of six cases. Journal of tropical medicine and hygiene, 1975, 78:59-62.

3. Lilly-Tariah OB, Ukoli CO, Nwana EJ. Cancer of the larynx in black Africans in Jos Nigeria. Central African journal of medicine, 1999, 45(2):40-2.

4. Marisoni R. Smoking control strategies in developing countries: a report of a WHO
Expert Committee. World smoking and health, 1984, 9(1):4-6.

5. Scully C, Cawson RA. Medical problems in dentistry, 2nd ed. Boston, Wright, 1987:528-9.

6. Locker D, Leake JL. Risk factors and risk markers for periodontal disease experience in older adults living independently in Ontario Canada. Journal of dental research, 1993, 72:9-17.

7. Tomar S, Asma S. Smoking-attributable periodontitis in the United States: findings 
from NHANES III. Journal of periodontology, 2000, 71(5):743-51.

8. Baab, DA, Oberg. PA. The effect of cigarette smoking on gingival blood flow in humans. Journal of clinical periodontology, 1987, 14:418-24.

9. Dietrich T, Bernimoulin J-P, Glynn RJ. The effect of cigarette smoking on gingival bleeding. Journal of periodontology, 2004, 75(1):16-22.

10. Barbour SE et al. Tobacco and smoking: environmental factors that modify the host response (immune system) and have an impact on periodontal health. Critical reviews in oral biology and medicine, 1997, $8: 437-60$

11. Zambon.JJ et al. Cigarette smoking increases the risk for subgingival infection with periodontal pathogens. Journal of periodontology, 1996, 67(Suppl.):1050-4.

12. Ainamo J. The seeming effect of tobacco consumption on the occurrence of periodontal disease and caries. Suomen hammaslaakariseuran toimituksia, 1971, 67:87-94.

13. Nwhator SO. Periodontal disease in smokers: a study of factory workers in Lagos state [Dissertation]. Nigeria, Faculty of Dental Surgery, National Postgraduate Medical College of Nigeria, May, 2005.

14. Sheiham A. Periodontal disease and oral cleanliness in tobacco smokers. Journal of periodontology, 1971, 42:259-63.

15. Bastian RJ, Waite IM. Effects of tobacco smoking on plaque development and gingivitis. Journal of periodontology, 1978, 28:460-3.

16. Suarez L Barrett-Connor E. Interaction between cigarette smoking and diabetes mellitus in the prediction of deaths attributable to cardiovascular diseases. American journal of epidemiology, 1984, 120:670-5.
17. Macgregor IDM. Toothbrushing efficiency in smokers and non-smokers. Journal of clinical periodontology, 1984, 11:31320.

18. Savage KO. Assessment of periodontal status of Nigerian factory workers in relation to cigarette smoking in Lagos. Nigerian quarterly journal of hospital medicine, 1999, 9(3):198-201.

19. Greene JC, Vermillion JR. Oral hygiene index: a method for classifying oral hygiene status. Journal of the American Dental Association, 1960, 61:172-8.

20. Ainamo $\mathrm{J}$ et al. Development of the World Health Organisation (WHO) Community Periodontal Index of Treatment Needs (CPITN). International dental journal, 1982, 32:281-301.

21. Cawson RA, Odell EW. Essentials of oral pathology and oral medicine, 6th ed. London, Churchill Livingstone, 1998:72-3.

22. Torrungruang $\mathrm{K}$ et al. The effect of cigarette smoking on the severity of periodontal disease among older Thai adults. Journal of periodontology, 2005, 76(4):566-72.

23. Serio FG, Hawley CE, eds. Manual of periodontics, 1st ed. Ohio, Lexi-Comp Inc, 2002:20-1.

24. Van Winkelhoff AJ et al. Smoking affects the subgingival microflora in periodontitis. Journal of periodontology, 2001, 72 (5):666-71.

25. Ramón J-M; Echeverría J-J. Effects of smoking on periodontal tissues. Journal of clinical periodontology, 2002, 29:771-6.

26. Gamal AY, Bayomy MM. Effect of cigarette smoking on human PDL fibroblasts. Attachment to periodontally involved root surfaces in vitro. Journal of clinical period ontology, 2002, 29:763-70.

27. Kingman $A$ et al. Errors in measuring parameters associated with periodontal health and disease. Journal of periodontology, 1991, 62:477-86. 
28. Miller NA et al. An analysis of the CPITN periodontal treatment needs in France. Community dental health, 1987, 4:41523.

29. Natto S, Baijoon M, Bergstorn J. Tobacco smoking and periodontal health in a Saudi Arabian population. Journal of periodontology, 2005, 76(11):1919-26.

30. Manson JD, Eley BM, eds. Outline of periodontics, 3rd ed. Oxford, ButterworthHeinemann, 1999.

31. Grondahl HG, Grondahl K. Subtraction radiography for diagnosis of periodontal bone lesions. Oral surgery, 1983, 55:20813.

32. Bragger $U$ et al. Computer assisted densitometric analysis in periodontal radiography. A methodological study. Journal of clinical periodontology, 1988 , 15:27-31.

33. Schwartz-Arad D et al. Smoking and complications of endosseus dental implants. Journal of periodontology, 2002, 73(2):153-7.

34. Ismail AI, Burt BA, Eklund SA. Epidemiologic patterns of smoking and periodontal disease in the United States. Journal of the American Dental Association, 1983, 106:617-21.
35. Haber $\mathrm{J}$ et al. Evidence for cigarettes smoking as a major risk factor for periodontitis. Journal of periodontology, 1993, 64:16-23.

36. Garcia RI, Chauncey HH. Longitudinal studies of ageing and oral health. Journal of dental research, 1991, 70:865.

37. Mehta JL, Saldeen TGP, Rand K. Interactive role of infection, inflammation, and traditional risk factors in arteriosclerosis and coronary heart disease. American college of cardiology, 1998, 31:12-7.

38. Mattila $\mathrm{KJ}$ et al. Association between dental health and acute myocardial infarction. British medical journal, 1989, 298:779-83.

39. Syrjanen $\mathbf{J}$ et al. Dental infections in association with cerebral infarction in young and middle-aged men. Journal of internal medicine, 1989, 225:179-84.

40. Offenbacher $S$ et al. Potential pathogenic mechanisms of periodontitis-associated pregnancy complications. Annals of periodontology, 1998, 3:233-7.

41. Hyman JJ, Reid BC. Cigarette smoking, periodontal disease, and chronic obstructive pulmonary disease. Journal of periodontology, 2004, 75:9-15. 